\title{
MODULARIZAÇÃO E DESIGN NA INDÚSTRIA AUTOMOTIVA: \\ O CASO DO MODELO FOX DA VOLKSWAGEN DO BRASIL
}

\section{MODULARITY AND DESIGN IN AUTOMOTIVE INDUSTRY: THE CASE OF THE FOX MODEL OF THE VOLKSWAGEN IN \\ BRAZIL}

\author{
Marcos Antonio Cardoso \\ Engenheiro Mecânico, Ms \\ Universidade Federal do Paraná \\ Programa de Pós-graduação em Engenharia Mecânica \\ Rua General Carneiro, 460, sala 813 \\ 80060-050, Curitiba, PR
}

Telefone: (41)9934.0503, E-mail: marcosrhcoach@yahoo.com.br

\author{
Virginia Borges Kistmann \\ Professora sênior \\ Universidade Federal do Paraná \\ Programa de Pós-graduação em Design \\ Rua General Carneiro, 460, sala 813 \\ 80060-050, Curitiba, PR \\ Telefone: (41)3360.5057, E-mail: vkistmann@ufpr.br
}

\begin{abstract}
RESUMO
À medida que a disputa pelos mercados torna-se global, surge uma pressão para que as empresas aprimorem-se, buscando maior eficiência e competência. Do contrário, surgem os riscos de comprometimento da própria sobrevivência. Nesse contexto, a gestão do design, nos seus níveis estratégicos, táticos e operacionais, associada à adoção de técnicas modernas de gestão da produção, serve de base para a aplicação da modularização. Neste artigo, estuda-se a relação entre o conceito de modularização e gestão do design, para melhorar o desempenho de uma montadora de automóveis. Tomando por base o estudo de caso realizado na unidade da Volkswagen do Brasil, na planta de São José dos Pinhais, utilizou-se pesquisa
\end{abstract}


bibliográfica, documental, observação do ambiente de trabalho e entrevistas informais. Como resultado, aponta-se para fatores importantes que visam à integração da gestão do design com as estratégias gerais da empresa para a modularização e o sistema produtivo adotado.

Palavras-chave: Modularização; Gestão do Design; Produção Automotiva; Volkswagen do Brasil.

\begin{abstract}
As long as market concurrency becomes a global issue, a pressure upon companies towards a better performance develops, aiming a better efficiency and competitiveness. So, on the contrary, risks of survival maintenance appears. In this context, design management, in its strategic, tactic and operational levels, together with modern techniques of production management, becomes the base for modularity application. This article studies the relation between the concept of modularity and design management, to improve the performance of an automotive manufacturer. Taking the case of a Brazilian Volkswagen plant in São José dos Pinhais, the discussion is made upon related bibliography, documental resources, observation and informal interviews. As result, presents some important factors aiming a better integration between design management together with general strategies towards modularity and production system.
\end{abstract}

Key-words: Modularity; Design Management; Automotive Production; Volkswagen do Brazil

\title{
1. INTRODUÇÃO
}

Inicialmente, é preciso definir o que se entende por design e sua gestão. O termo design, etimologicamente com um significado muito amplo, é utilizado por diversas áreas do saber: na administração, fala-se em Escola de Design, Design de Estratégias; na Engenharia, Engineering Design, um processo de criação de um sistema, componente ou processo para atender necessidades esperadas; e no campo do Design propriamente dito, Design de Produtos ou Gestão do Design, por exemplo.

De modo amplo, a atividade de design, como planejamento ou projeto, aplica-se tanto ao que se consideram atividades relacionadas à engenharia como às do design industrial ou design de produtos, no Brasil, referente à formação em Design, Desenho Industrial ou de Design de Produtos.

Para o ICSID (2008), design é considerada:

uma atividade criativa, cujo objetivo é estabelecer as qualidades multifacetadas dos objetos, processos, serviços e seus sistemas em todos os ciclos de vida. Dessa forma, design é o fator central da humanização inovadora de tecnologias e o fator crucial 


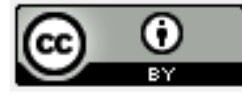

de mudança cultural e econômica. [...] Dessa forma, design é uma atividade que envolve um largo espectro de profissões, nas quais produtos, serviços, gráficos, interiores e arquitetura tomam parte. (Tradução livre dos autores.)

Além da base etimológica comum da designação "design" nas diversas áreas, a visão sistêmica que se desenvolveu nos estudos relativos ao processo produtivo fez com que essas áreas passassem a ter seus limites superpostos. O campo da engenharia, por exemplo, foi pouco a pouco subdividindo-se em vários sub-ramos, de acordo com o foco estabelecido e, assim, surgiram suas especializações. A forte relação com as ciências exatas foi, pouco a pouco, dando espaço para novos aspectos, incluindo os das ciências humanas, tais como dados psicológicos, sociológicos e fisiológicos. Porém, o sentido que se toma ao referir-se à atividade de design de produtos, design gráfico ou design de móveis diz respeito a uma prática profissional que engloba não apenas os fatores estéticos e ergonômicos, focalizada no projeto conceitual, mas também aspectos tecnológicos e comerciais, desde a sua fase estratégica até a sua operacionalização. Nessa atividade, de modo similar à engenharia, passou-se a considerar a atividade como um processo, adotando-se a designação "gestão do design", cujos primeiros trabalhos surgiram com Farr em 1966, que levaram a fundação em 1975 do Design Management Institute, em Bóston, junto à Harvard University, nos Estados Unidos da América.

Na gestão do design, o Processo de Desenvolvimento de Produtos (PDP), largamente utilizado na Engenharia, é um dos aspectos a ser considerado, relacionado ao nível denominado Design Funcional. A gestão do design é o processo de coordenação das atividades integradas de design que englobam a definição da companhia, seus consumidores e investidores no processo de diferenciação, buscando-se o sucesso comercial (WOLF, 1994). Para tanto, a gestão do design, além do nível funcional, subdivide-se em dois níveis: estratégico e operacional (MOZOTA, 2003), ou ainda: design estratégico, design tático e design operacional (SANTOS, 2000). Essa nova classificação fundamenta-se na mudança do modelo de gestão fordista para o modelo organizacional flexível, que encoraja a iniciativa individual, a independência e a tomada de risco (MOZOTA, 2003).

Nesse contexto, para o atendimento ao consumidor de modo mais eficaz, passou-se a considerar, como uma das modalidades de atuação, a customização em massa (cunhada por Pine em 1994), servindo esta como uma das premissas para o sucesso das empresas globalizadas. Assim, a modularização, nas sua acepção plena, surgiu como um modo de 
projeto que auxilia na configuração de produtos que venham a atender mercados diversos. É esse, pois, o encaminhamento deste estudo.

Especialmente na indústria automotiva, esses aspectos possuem grande relevância, pois as alterações em modelos existentes e o lançamento de novos produtos fazem parte do seu planejamento regular. Com isso, novas tecnologias são introduzidas, o processo é aprimorado, os custos reduzidos e o consumo ampliado; os engenheiros e designers automotivos, no sentido em que são formados os profissionais que executam o design dos carros, como na formação em mestrado do Royal College of Art, na Inglaterra, incumbem-se de parcela da tarefa, na medida em que buscam adaptar os modelos a novos processos, revêem a forma para reduzir o custo e melhorar a participação no mercado, introduzem novos elementos para ampliar a "família" ou projetam um novo produto (TOVEY et all., 2003). A atuação da empresa General Motors nos anos 1930, por exemplo, é um marco na modificação do panorama das empresas (SPARKE, 2002), com a preocupação com o atendimento das expectativas dos consumidores. Engenheiros e Designers, desde então, introduziram novos elementos, como componentes, cores, frisos, apliques, no intuito de motivar o aumento da demanda, procurando, gradativamente, produzir aquilo que os clientes queriam. Em paralelo, novos materiais e novos processos produtivos foram, pouco a pouco, sendo incorporados, modificando a indústria automotiva, o Processo de Desenvolvimento de Produtos e o Processo de Gestão do Design.

Nesse contexto, o processo de modularização em massa foi, inicialmente, liderado pela engenharia, na busca por resultados inovadores, e passou a ser encarado de modo mais integrado a partir do acirramento da disputa por mercado, entre as montadoras, incluindo-se hoje, inclusive, aspectos da modularização voltados para o desempenho financeiro. Assim, a diferenciação dos produtos vem tendo um crescimento ininterrupto na indústria em geral e, em particular, no setor automotivo. Hoje, as empresas atuam guiadas por um processo de fragmentação da demanda, a partir da divisão do consumidor em várias categorias, para as quais se oferece uma oferta cada vez mais diversificada de modelos, versões e características.

No Brasil, um novo cenário de competição, criado a partir da abertura do mercado e introduzido a partir dos anos 1990, fez com que o mercado consumidor ficasse muito mais exigente; o grau de diversificação dos produtos tornou-se cada vez maior e o ciclo de vida cada vez menor. Isso resultou na necessidade de integração dos diversos setores da empresa, como vendas, design, marketing e produção (MAGALHÃES, 1997). Acompanhando as modificações que passaram a acontecer no cenário mundial, demandou-se uma mudança na 
mentalidade empresarial que, então, objetiva uma visão mais pró-ativa para inovar com o desenvolvimento do produto, contemplando a preocupação com a satisfação do cliente, a manufaturabilidade do produto, o meio ambiente, os aspectos ergonômicos e a reciclagem, entre outros. Dessa forma, surgiu a estratégia de modularização, que passou a ser objeto de preocupação dos engenheiros e designers; por seu intermédio, não apenas a produção tornouse mais racional, inclusive com menor impacto ambiental, mas também possibilitando um atendimento aos consumidores mais individualizados.

Neste trabalho, portanto, discute-se a modularização e a gestão do design, buscando-se a relação entre as duas competências, através de um estudo de caso, no projeto do carro Fox, da Volkswagen do Brasil, produzido na BUC (sigla em inglês para Unidade de Negócios de Curitiba), cuja planta localiza-se em São José dos Pinhais, município vizinho à Curitiba. $\mathrm{O}$ estudo de caso foi realizado no intuito de verificar como a gestão do design e a modularização acontecem em uma situação real e comparar tal situação com a literatura na área, contribuindo para o avanço teórico do tema.

\section{A MODULARIZAÇÃO}

A modularização vem sendo buscada pelas empresas porque proporciona uma série de vantagens estratégicas que, quando bem desenvolvidas e administradas, podem proporcionar um diferencial competitivo significativo. A modularização é uma ação intencional, que possibilita o intercâmbio dos componentes de um produto, gerando uma faixa ampliada de produtos finais (SANCHEZ \& COLLINS, 2003; SANCHEZ, 2002).

O termo módulo descende da palavra em latim modulus, que corresponde a uma medida padrão de comprimento. Do conceito de módulo, derivam os termos modularização e/ou modularidade (PELEGRINI, 2004).

Blackenfelt (2001) argumenta que o conceito de produção em série apóia-se em princípios construtivos modulares, desde a produção do automóvel Ford Modelo T. O termo “produto modular”, tradicionalmente, refere-se a produtos que são projetados para satisfazer a uma variedade de requisitos com várias combinações por meio de componentes padronizados. Assim, a maior proposta por trás da modularização é a produção de uma variedade de produtos racionalizados. Dentro desse conceito amplo de modularização, no desenvolvimento 
de produtos ou no design operacional, é necessário se apoiar na variabilidade a partir de família de produtos, decorrentes do desenvolvimento de plataformas.

No conceito atual, Huang (2000) caracteriza os módulos como sendo os componentes, ou conjunto de componentes, cujas especificações de interfaces e interações seguem uma padronização pré-definida. O módulo é uma unidade básica do produto que possui interfaces padronizadas, possibilitando procedimentos como testes e pré-montagem, sem que haja interferência no produto como um todo. Sintetizado, na descrição de Fixon (2005), módulo é o agrupamento de componentes que possui um número definido e padronizado de interfaces.

Baseado nas interações com o produto, três categorias de modularização foram definidas por Sako e Murray (2000): dois ou mais módulos são combinados com uma plataforma básica, criando variantes de produtos pertencentes à mesma família; várias plataformas básicas, dividindo o mesmo módulo, formam diferentes variantes de produto pertencentes a diferentes famílias; uma plataforma básica pode ser trocada por um ou vários módulos. Este tipo permite a variação no número e na localização dos módulos.

A modularização é, portanto, uma propriedade que resulta em variáveis diferentes no projeto de produto, na produção e na organização do trabalho, bem como no relacionamento entre empresas (SCHILLING, 2000). Nesse sentido, Pelegrini (2004) ressalta que, sob o ponto de vista da gestão do design, essas estratégias devem estar alinhadas com as atividades táticas da empresa na incorporação do design como uma de suas competências centrais, como valor agregado. Assim, a modularização deve ser compreendida dentro de todo o processo de gestão, sendo uma ferramenta essencial, entre outras coisas, ao estabelecimento de novos produtos orientados para a customização.

Conforme Fixon (2005), a modularização poderá estar voltada para uma ou mais formas, descritas a seguir: modularização para projeto; modularização para uso; e modularização na produção.

\subsection{A modularização no projeto}

Como foi visto, do ponto de vista do projeto de produtos, a modularização é classicamente obtida a partir de uma arquitetura modular. Sanchez (2002) explica que a arquitetura modular do produto é aquela que é projetada para possibilitar a combinação e o encaixe de diferentes componentes, objetivando configurar o maior número possível de variações do produto (PELEGRINI, 2004). 
$\mathrm{Na}$ modularização no projeto, as arquiteturas modulares ajudam as empresas a competir ao longo das dimensões que são mais relevantes, tais como a crescente individualização do consumo, as mudanças tecnológicas cada vez mais rápidas e a necessidade de adaptação de diversos fornecedores. Neste caso, a modularização exerce profundo impacto sobre a estrutura setorial, pois possibilita que organizações independentes, não integradas, vendam, comprem e montem componentes e subsistemas. Quando isso acontece, as empresas são capazes de misturar e combinar componentes dos melhores fornecedores, a fim de responder de maneira conveniente às necessidades específicas de cada um dos clientes (BLACKENFELT, 2001).

Além disso, com a arquitetura modular, os engenheiros e os designers possuem maior liberdade para projetar seus módulos, sem dependência direta de outras etapas de projeto. Devido a essa independência, aumenta-se a intensidade de inovações no projeto, pois com isso podem ser criados e testadas diferentes soluções dentro de seus próprios módulos, devendo-se respeitar somente as regras visíveis ou interfaces do sistema (SANCHEZ, 2002).

Conforme as suas características, ao alinhar-se de modo particular com o processo de customização, a modularização possibilita a atuação de modo pleno ou parcial. Na modularização plena, cada consumidor é atendido individualmente, enquanto que, na modularização parcial, os consumidores são agrupados em nichos ou estilos de vida. No caso da produção em massa, o grau de modularização faz com que a customização tenda ao zero. Nesse caso, ela é identificada como customização em massa (PINE, 1994).

\subsection{A modularização na produção}

Do ponto de vista produtivo, a modularização não é um conceito novo, como afirma Blackenfelt (2001). Ela já era usada na indústria automotiva com o Modelo T, criado por Henry Ford, e no modelo Fusca da Volkswagen. O modelo T, possuindo um sistema de produção modular bastante avançado para a época, alcançou a venda de 8 mil unidades. (WOMACK, 1992).

Atualmente, com o novo cenário econômico mundial, a indústria automotiva incorporou definitivamente as práticas de racionalização e redução de custos, intensificando os processos de globalização, de hierarquização dos fornecedores, de modularização, de consórcios e condomínios industriais, os quais alteraram profundamente a dimensão industrial de todo o negócio (ARBIX \& VEIGA, 2004). 
A partir dos anos 1990, o Brasil foi um dos países do mundo que mais recebeu unidades industriais de montadoras do setor automotivo. Tal processo encontrou um campo fértil para experimentações de arranjos organizacionais que atribuem a determinado tipo de empresa de autopeças um novo papel, qual seja o de capitanear a modularização. Esse conceito, no qual o fornecedor passou a ser conhecido como "sistemista", "modulista" ou "moduleiro", é protagonista de primeira linha nos arranjos conhecidos como "consórcio modular" ou “condomínio industrial” (SALERNO et al., 1998; SALERNO, 2002).

Na medida em que a produção de veículos como um todo deixou de ser a maior fonte geradora de lucro para as montadoras, essas têm voltado sua atuação para seus núcleos de competências (do inglês, core competences), ou seja, aquelas atividades específicas da cadeia, na qual o valor agregado é maior e tem mais possibilidades de expansão como, por exemplo, o projeto, a montagem e o composto marketing, financiamento e venda (HAMEL; PRAHALAD, 1995).

Conforme Heikkkilä et all. (2002), a modularização é um conceito bem vantajoso em um grande número de negócios com sistemas complexos. No processo, o módulo é visto como um agrupamento de componentes montados e fornecidos em uma única unidade. Essa mudança implica oportunidades de fornecimento para os fabricantes de componentes.

\subsection{A modularização para o uso}

A modularização possibilita uma variedade maior de produtos, com respostas rápidas às mudanças de desejo e às necessidades dos consumidores, atendendo a usos diversos. Desse modo, a modularização permite a produção de diferentes produtos pela combinação de componentes padronizados (SAKO \& MURRAY, 2000).

Produtos modulares são produtos, sistemas ou componentes que executam suas funções através da combinação de diferentes módulos (BLACKENFELT, 2001).

A modularização pode ser uma das estratégias para obter a diferenciação dos produtos e a customização, além de proporcionar uma série de outras vantagens, sejam elas do ponto de vista ambiental, sejam por razões de redução de custo. Para tanto, as empresas devem desenvolver uma arquitetura modular, que gere plataformas de produtos e, em última instância, gerem produtos modulares (PELEGRINI, 2004). Quanto mais opções ofertadas, teoricamente, mais chance de atender-se aos anseios dos consumidores. 


\section{A GESTÃO DO DESIGN}

De acordo com Santos (2000), pela sua atuação como ferramenta estratégica nos mercados cada vez mais competitivos, a gestão do design tem sido reconhecida como importante para os diversos tipos de empresas, sejam elas indústrias, organismos, instituições ou prestadoras de serviços. A gestão do design pressupõe assumir uma atitude pró-ativa sobre a imagem que o mercado tem das empresas (TEIXEIRA, 2005). Por isso, segundo Camacho (2004), podem-se considerar, na Gestão do Design, os níveis Estratégico, Tático ou Funcional e Operacional como níveis Estratégico, de Processo e de Projeto.

Assim, no nível estratégico, o design constitui-se como uma das competências centrais das empresas, auxilia na inovação, fortalece o seu papel como cultura empresarial, aproximando a empresa dos consumidores e fortalecendo a sua imagem, ao lado do branding. Por isso,

Com o forte surgimento, na última década, da profissão de Design, ou Gestão do Design, as empresas mais competitivas do mundo não só utilizam o design para gerar diferenças em seus produtos, mas o design converteu-se em um componente estratégico chave nas empresas, que possibilita a competitividade de maneira sustentável. (CAMACHO, 2004, p. 8). (Tradução livre dos autores)

Para Magalhães (1997), o design no nível estratégico é uma forma de ação do profissional de design direcionada à gestão do design nas empresas, ou seja, que participa da orientação da política do design, apoiada por análises de fatores internos e externos às empresas, em um nível hierárquico mais alto dentro dessas, e desde as primeiras fases do desenvolvimento de produtos.

No nível tático, funcional ou de processo, atua de modo a integrar a atividade de design com outras atividades desenvolvidas na empresa, fazendo com que os diversos profissionais relacionados ao design, no seu sentido amplo, interajam. Esse nível dá suporte à atividade de design, trata da atuação do processo de design em relação aos demais processos da empresa e integra-o com as demais áreas (CAMACHO, 2004). Ele atua de modo a controlar, coordenar e aprovar todas as atividades de design, visando atingir a estratégia empresarial, fazendo conexões com as áreas de fabricação, comunicação, pesquisa e desenvolvimento da empresa (WOLF, 2003).

No nível operacional, atua de modo a gerar produtos, serviços e elementos de comunicação que reflitam os pontos fortes da empresa. Um exemplo de boa utilização do design operacional é o encontrado na empresa Wilkhahn (WOLF, 2002). 


\subsection{A gestão do design e a modularização}

Para aumentar a competitividade, a gestão do design deve alçar uma condição estratégica, permeando todos os níveis gerenciais (MOZOTA, 2003). Dessa forma, deve privilegiar a modularização, caso considere-a como estratégica.

No contexto da gestão do design, a modularização está vinculada à adoção de uma política de aproximação do consumidor e de customização. Para tanto, ela atua tanto nos seus níveis estratégicos, táticos (ou funcionais) e/ou operacionais. Além disso, ela deve ser vislumbrada sob dois aspectos essenciais: a) associada à customização, como pré-estágio da modularização, voltada para o conhecimento das demandas individuais ou grupais dos consumidores; b) secundariamente, na geração dos produtos modulares, apoiados em plataformas de produtos e na arquitetura modular. Assim, do ponto de vista do design tático ou funcional, a modularização demanda a geração de ferramentas de projeto e protocolos de ações que integrem o processo na organização. Sob esse aspecto, as empresas precisam de pessoal competente em nível gerencial, que consiga introduzir tanto as ferramentas já existentes, quanto criar novas ajustadas às características do seu produto.

Ações específicas são também necessárias no design operacional tanto em relação à comunicação interna, quanto externa da empresa. Produtos e serviços precisam igualmente ser obtidos com a inclusão dos valores preconizados pela empresa, associados aos conceitos de customização e modularização. Segundo WOLF (2003), na comunicação interna da empresa, a gestão do design torna-se importante ao buscar desenvolver os elementos que configuram os seus diversos suportes. Dessa maneira, desde elementos de sinalização de fábrica que orientam os funcionários a respeito da modularização, até a facilitação do processo de mudança contínua, como suporte de informações a serem veiculadas, devem ser integrados. Por outro lado, na comunicação externa, como ponte entre a fábrica e o consumidor, a modularização é uma temática a ser disseminada, facilitada e incorporada. No caso da modularização, além dos ganhos obtidos pela modularização em si, as informações devem estar visíveis para o consumidor.

\subsection{A gestão do design no setor automotivo}

Design automotivo é uma atividade profissional do campo do design, com formação específica, que se responsabiliza pelo desenvolvimento da aparência e, em alguns casos, pelos aspectos ergonômicos, especialmente de veículos motorizados. Essa prática profissional é 
desenvolvida, em geral, por grandes times, que incluem também os engenheiros automotivos. Além dos aspectos estéticos do veículo, o design automotivo atua também na formação do conceito do carro como, por exemplo, no caso do modelo Fox da Volkswagen do Brasil.

Hoje, a atividade de design no setor automotivo considera, predominantemente, os aspectos práticos, funcionais, estéticos e comportamentais, associados à produtividade, aos aspectos de reciclagem, à individualidade e ao ciclo de vida do produto, na criação e no desenvolvimento de veículos (LARICA, 2003). Trata-se, portanto, de uma abordagem com foco principal nos aspectos operacionais do design.

Porém, conforme a intensificação da competição entre fabricantes automotivos aumenta, fica fácil perceber que a meta do design não é apenas colocar no mercado um novo modelo, mas fazê-lo também de forma rápida, para que ele se coloque em curto período de tempo, e antes da concorrência, diante dos consumidores. Para Silva (2001), a indústria automotiva passa por um período de transformação, de experiências e tentativas para se fortalecer internacionalmente. Nesse sentido, as estratégias de produto vêm se voltando para o mercado local, desenvolvendo carros populares fortes nas vendas nacionais, ou para o exterior, com modelos globais. Por isso, a customização dos produtos tem se tornado uma das opções das montadoras para ganhar escala de produção (SALERNO et al., 1998) e, conseqüentemente, diferenciar-se da concorrência, o que afeta diretamente a gestão do design.

Pine (1994) considera que a customização é reforçada por meio do conceito da modularização, focada em variedade e personalização, através de flexibilidade e respostas rápidas, o que interfere diretamente no design automotivo. Assim, conforme Larica (2003), a compra de um automóvel é decidida, com freqüência, devido ao gosto estético, pois as funções práticas supõem-se ótimas, na medida em que esse é um setor já maduro. O resultado do projeto de um carro reflete aspectos internos de uma ação para atingir o valor superior disponível para os consumidores e para a sociedade.

Seguindo a classificação das estratégias de Porter (1989), o design ao nível operacional pode contribuir para três tipos básicos de projeto: um voltado para a estratégia que busca a liderança através do menor custo, aplicado à racionalização, sistematização e otimização do produto, e os dois outros voltados à diferenciação e à segmentação, relacionados à estratégia que busca a liderança através da satisfação das necessidades do mercado. No segundo caso, a atuação do design no nível operacional poderá acontecer desde o levantamento das necessidades até a transformação das necessidades em produtos, relacionando-se à customização e à modularização. 
Existem várias metodologias usadas em projetos de produtos industriais, e os modelos de desenvolvimento de produtos são bastante similares; porém, os objetivos, quando colocados em prática, são diferentes. Logo, os resultados, também tendem a apresentar diferenças. A atividade de projeto, por suas características e peculiaridades próprias, desdobra-se em uma seqüência de eventos, que seguem uma ordem cronológica, formando um modelo que, quase sempre, é comum a todos os projetos, como os trabalhos de autores do campo da metodologia projetual, tais como: Gugelot, Archer, Löbach e Bürdek. Porém, de modo geral, conforme a literatura da área, para execução de um projeto automotivo, o design operacional apóia-se nas seguintes fases: planejamento e pesquisa de mercado; desenvolvimento do conceito; estabelecimento das especificações requeridas para o produto; desenho dos sistemas e formação da estrutura do produto; estabelecimento da organização operacional; síntese do projeto (documentação).

Além disso, atualmente, o design automotivo no nível operacional apóia-se no uso de inúmeras ferramentas de projeto, cores e formas, texturas, tons e proporções relativas, relacionando interativamente os elementos em função de um significado, no qual inúmeras variáveis interagem na formulação de um todo coerente (LARICA, 2003). Nesse caso, a modularização precisa se integrar ao estilo do conjunto.

Conforme descreve o mesmo autor, uma das metas do design automotivo, deve ser o desenvolvimento de uma linguagem estética, um estilo próprio, que faça com que a expressão da potência, a impressão de segurança e a sensação de agilidade aflorem na configuração do produto e configurem-se em uma experiência tangível tanto para o usuário, como para o observador do produto. Então, no design de um carro, na sua configuração, os valores sociais e pessoais do consumidor são elementos fundamentais. Nesse sentido, Larica (2003) destaca que a forma é a espinha dorsal do processo de criação do automóvel, resumindo os sonhos e as ambições dos consumidores.

Dessa forma, a percepção da identidade do produto e da empresa está grandemente influenciada pela atuação do design, fazendo com que a habilidade de reconhecer e reagir emocionalmente à imagem de um objeto depende de como o objeto é desenhado, depende da impressão visual da sua forma; por isso, a gestão do design torna-se uma forma mais adequada de ver-se o processo. Além disso, o projeto de um carro e o seu resultado em termos de produto devem atingir não apenas um aspecto formal agradável, mas também um valor agregado superior ao daquele disponível para os consumidores. Alguns atributos apresentados por Trueman (1998) enfatizam: atuar como ferramenta competitiva e estratégica; diferenciar 
produtos; atribuir-lhes identidade; incorporar aspectos estéticos, relacionados à qualidade e ao estilo; agregar valor; e reduzir a complexidade. De forma complementar, a identificação do foco das aplicações de design, tais como valor, imagem corporativa, processo e produção, visariam garantir uma gestão equilibrada das aplicações do design.

Portanto, a gestão do design de veículos automotivos deve considerar todos esses aspectos. Em particular, no caso dos módulos automotivos, foco deste estudo, os aspectos funcionais e estéticos seriam fundamentais para o desempenho competitivo e estratégico.

\section{O ESTUDO DE CASO}

O estudo foi realizado em uma organização do setor automotivo, empresa que historicamente liderou o mercado nacional de veículos, mas que, nos últimos anos, vem sofrendo a ação acirrada da concorrência, com reflexos na perda de sua fatia do mercado (do inglês, market share), a Volkswagen do Brasil. Através do estudo de caso realizado na planta de São José dos Pinhais, buscou-se verificar como a modularização e a gestão do design contribuem para a estratégia da empresa no caso do projeto do veículo Fox.

Para tanto, foram realizadas entrevistas, aplicados questionários, consultada a documentação interna e externa da empresa, resultando nos dados apresentados a seguir.

A partir de 1993, o grupo Volkswagen desenvolveu a estratégia de plataformas mundiais e centros de excelência, que compõem a base do modelo mundial de sua produção. A necessidade de criação dos centros de excelência justificou-se a partir da estratégia global da empresa, isto é, como algumas fábricas do grupo são donas das plataformas, elas próprias fabricam determinadas plataformas, conforme seus centros de excelência, e as outras recebem conjuntos através de processos de importação e exportação (ANDRADE, 2003). Nesse sentido, uma plataforma congrega o conjunto motriz (do inglês, power train), motor, câmbio, eixos e os demais componentes mecânicos, incluindo assoalho e caixas de rodas, dianteira e traseira. As plataformas permitem gerar famílias de produtos, o que se alinha diretamente com a modularização.

No caso da Volkswagen, existem no mínimo $35 \%$ de peças comuns a todos os modelos da mesma plataforma, o que proporciona uma grande economia de escopo, além de permitir uma escala nos volumes de produção (ANDRADE, 2003). Sendo os carros mundiais obtidos a partir da mesma plataforma, existe uma simetria tecnológica entre as fábricas que 
produzem os mesmos modelos. Nesse modelo de produção, além da tendência de fábricas especializadas em plataformas (embasadas no conceito global de fornecimento de componentes) e do forte aparato logístico que suporta o modo produtivo (com a utilização de uma linguagem técnica única entre as fábricas), a comunicação dentro do processo de programação da produção, das fábricas e dos diversos componentes transnacionais entre si, em tempo e espaço, permite e viabiliza o macro-processo de focalização no cliente. Dentro do conceito de trans-nacionalidade de produção, as fábricas que montam carros sobre determinadas plataformas compraram seus componentes dos centros de excelência.

Uma das estratégias competitivas da Volkswagen está apoiada na modularização, visto que a meta é diminuir investimentos e gastos com desenvolvimento e lançamentos (ANDRADE, 2003). Para que isso ocorra, é importante que haja evolução permanente: da estratégia de plataformas para uma estratégia de produtos modulares. Dessa forma, serão empregados mais componentes iguais em diferentes gamas de modelos. Segundo José Ignácio López de Airriortua, um dos principais executivos da empresa, citado por Andrade (2003), a criação da modularização pode ser denominada como a terceira revolução industrial ou a substituição da linha de montagem criada por Henry Ford, na qual a base do sistema de modularização é a terceirização.

Como primeira forma adotada para enfrentar a concorrência e aumentar a sua participação no mercado, a Volkswagen do Brasil adotou uma estratégia de inauguração de novas plantas mais modernas. Assim, em janeiro de 1999, foi inaugurada a denominada, popularmente, Fábrica da Volkswagen-Audi, em São José dos Pinhais, região metropolitana de Curitiba. A Unidade de Negócios de Curitiba (BUC) foi criada para dar mais autonomia e transparência à gestão da nova unidade, dentro de um projeto maior de modularização da empresa, com unidades que se inter-relacionam, mas possuem, ao mesmo tempo, independência administrativa. No processo de reestruturação do grupo Volkswagen, em 1990, a especialização das fábricas por modelos (famílias de carros) e componentes (transmissão, motor) caracterizou a base da competência da empresa. O processo de reestruturação produtiva levou a empresa a adotar o modelo de produção enxuta (ANDRADE, 2003).

Partindo dos processos de reestruturação produtiva e da adoção de novas formas de gestão da produção com o objetivo da redução da mão-de-obra, a Volkswagen introduziu a desintegração vertical como modo de aumento de competitividade. Essa desintegração vertical foi o primeiro passo para a modularização, atuando em consenso com o apontado na 
literatura, ou seja, as empresas vêm buscando colocar a modularização como uma das competências essenciais (ANDRADE, 2003).

Nesse sentido, buscando a orientação pautada no conceito de centros de excelência, visando à expansão e à reativação da demanda, de modo inovador e com um posicionamento global, a Volkswagen do Brasil, apoiada pela Volkswagen Mundial, aprovou o início do projeto Tupi, que veio originar as modificações gerais que atingiram a empresa tanto em termos administrativos, como mercadológicos e fabris, bem como o desenvolvimento do produto Fox (VEIGA, 2003). O projeto desse carro partiu da concepção de que um novo modelo era necessário para competir com os demais concorrentes, integrando desde o seu projeto, sob o ponto de vista do produto, até os processos produtivos no qual ele iria se inserir. Para tanto, reduzindo custos, partiu de uma plataforma modular já existente e desenvolveu um novo modelo, denominado Fox (VEIGA, 2003).

Na visão de Maergner (2004), seu presidente, o único jeito de sair da crise em que se encontrava a empresa seria o lançamento de um novo produto dentro da concepção modular.

Com a política de recuperação do mercado, a Volkswagen do Brasil decidiu investir no desenvolvimento desse novo modelo que, inicialmente, teve o nome Tupi ou VW-249 e, posteriormente, Fox. Segundo Krueger (2003), a escolha do nome Fox foi definida porque o mesmo é fácil de pronunciar e, além disso, sugere um carro veloz, ágil e compacto. Em inglês, a palavra significa raposa: um animal esperto, astuto e sagaz.

O Fox foi o primeiro carro nacional equipado com um motor 1.0, que utiliza tecnologia bi-combustível (total flex). Inicialmente, foi lançado em quatro versões: City, Plus, Sport Line e, o mais novo, Cross Fox. Nas três últimas versões, também apresenta opção de motores 1.6 bi-combustível. Existe, ainda, uma versão com motor $1.08 \mathrm{v}$, naturalmente aspirado, com 72cv, o mais potente do mercado, (VOLKSWAGEN, 2003a).

Com uma concepção formal nova, a carroceria do Fox pode ser definida como um misto de veículo compacto com soluções de mini-van. O conceito desenvolvido pelos designers no projeto do Fox recebeu o nome de Designer Around the Passengers (desenhado ao redor dos passageiros) e fez com que os designers da Volkswagen do Brasil desenhassem primeiro o interior do carro (posicionando confortavelmente cinco passageiros, gerando todos os espaços possíveis e acrescentando elementos de praticidade e versatilidade necessários para o transporte de uma família) para, a seguir, desenvolver o seu exterior. Além disso, os designers deram ao novo carro um destaque especial no aproveitamento completo e inteligente do espaço interno (VOLKSWAGEN, 2003a). 
A partir de quatro grupos de consumidores, definidos por meio de "clínicas" (atividades de pesquisa de mercado, realizadas em um ambiente fechado, nas quais os produtos são analisados pelos consumidores), o carro teve sua versão configurada em uma família, que inclui o Fox Hatch, com tecnologia de bi-combustível e motorização de 1.0 e 1.6, e o Cross Fox, que prevê o segmento esportivo fora de estrada, que já estava previsto no projeto original. Dessa forma, surgiu a expansão de um modelo específico para uma família de veículos, configurada por meio de uma plataforma comum a todos os modelos (VOLKSWAGEN, 2003a). Como se observa, a modularização está inserida de maneira a reduzir custos de projeto, custo de desenvolvimento de fornecedores, custo de treinamento da mão-de-obra, entre outros.

O projeto modular não seria possível se não houvesse respaldo de um sistema de produção flexível. Em 2003, a BUC já trabalhava com o BUC Production System (BPS), ou Sistema de Produção BUC, desenvolvido a partir de conceitos tirados do sistema de produção enxuto e consolidado na modularização (ANDRADE, 2003). Posteriormente, a empresa incorporou o conceito de equipes autogerenciáveis, batizando-o de $V W$ Benchmark. O conceito piloto foi implantado na BUC, com a intenção de que fosse adotado por outras plantas do grupo. O BPS, aliado ao VW Benchmark, é um conceito organizacional padronizado, cuja filosofia está baseada na integração dos empregados com o processo produtivo. A empresa desenvolveu o sistema para assegurar a competitividade e a sobrevivência, em um mercado cada vez mais competitivo; para tanto, foi necessário o aperfeiçoamento de produtos, serviços e atividades. Com a implantação, foram revistos e melhorados os conceitos, os métodos e a forma como se organizam e fabricam os produtos.

O planejamento da fábrica prevê o envio dos módulos, através de seus "sistemistas", para áreas próximas ao posto de trabalho na linha de montagem. A partir daí, a Volkswagen controla o seqüenciamento, a sincronização e a montagem. Outra inovação em termos de sistemas produtivos está presente na planta, onde se verifica uma diferente forma de observar o fluxo de materiais, de informações e de gerenciamento da produção (figura). Nessa planta, pode-se ver o layout em forma de "Y", no qual todos os setores convergem para um Centro de Comunicações (ANDRADE, 2003). 


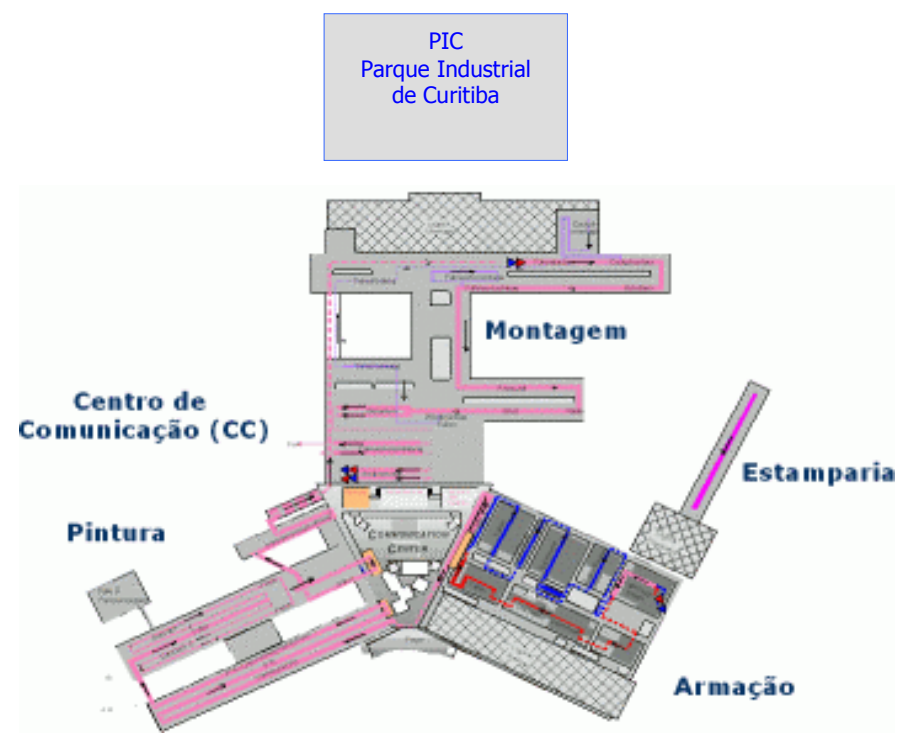

Figura: Layout da planta de São José dos Pinhais., B.J, Fonte: VOLKSWAGEM (2005).

Na estratégia de modularização da BUC, o Fox foi criado dentro do segmento de carros compactos. Os elementos destacados pela empresa, segundo Veiga (2003), são o espaço interno, a forma moderna e robusta, a economia com a tecnologia bi-combustível, o painel com conta-giros e a direção com regulagem de altura.

Como o design operacional (SANTOS, 2000) na Volkswagen do Brasil não está localizado junto à Unidade de Negócios de Curitiba (BUC), e sim centralizado na Unidade de Negócios de Anchieta (BUA), o design operacional do veículo Fox foi feito em São Paulo. Lá, o departamento de design da Volkswagen do Brasil está dividido em três setores, que trabalham simultaneamente no lançamento e na mudança de modelos, com equipes de várias plantas do grupo Volkswagen. Esses setores estão relacionados a seguir (VEIGA, 2003). 
- Package: os seus especialistas têm o principal enfoque na ergonomia, visando um melhor uso das áreas internas dos veículos. Por conseqüência, também são analisados outros itens, tais como acesso, visibilidade, volume de bagagem, bem como os mais diversos mecanismos de engenharia, incluindo a trajetória de bancos, tampas e portas. Outra responsabilidade desse setor é analisar referências dos atuais veículos da marca e dos concorrentes com o objetivo de melhorar as características de um novo projeto. A função de buscar soluções tecnológicas junto à engenharia e aos fornecedores também é responsabilidade do departamento de design.

- Shape: os seus especialistas têm a função de definir a configuração geral do veículo. Eles possuem bastante liberdade de criação. Em um primeiro momento, as propostas não têm vínculos de proporções ou qualquer viabilidade técnica. É importante caracterizar, ainda, que os designers têm uma preocupação não só com a carroceria, como também exploram todas as possibilidades para propostas de interior, tais como painel, portas internas e bancos. Colour and Trim: a tarefa de seus especialistas é escolher materiais para aplicação em cada uma das peças aparentes dos veículos. Seja na escolha de um plástico, metal, tecido, carpete, vinil, couro ou outro aspecto, sempre é preciso manter uma lógica formal, como também seguir as tendências de moda.

Após a aprovação da configuração geral do veículo, com a aprovação dos desenhos e das medidas do carro, entra em ação o trabalho dos modeladores, responsáveis pelo exterior do carro, liderados pelos designers. As primeiras maquetes, modelos em escala, são produzidas em 1:4. Em média, dez propostas são apresentadas à diretoria da empresa. Desse total, saem duas principais, que são montada em escala 1:1. O modelo escolhido é apresentado em plastilina, uma espécie de barro, na qual é detalhada a área do ambiente do motorista: cockpit (conjunto de painel e assentos dianteiros), lateral, bancos etc. Esse trabalho é desenvolvido e acompanhado em conjunto com os departamentos de engenharia, manufatura, finanças e fornecedores, até o lançamento do produto, garantindo que todos os ideais e conceitos do design, além da viabilidade técnica e econômica, sejam atingidos. Para a realização do trabalho de design, a Volkswagen do Brasil utiliza uma ferramenta de projeto chamada Catia. O Catia é um sistema de CAD/CAM/CAE modular e interativo, integrado em estações de trabalhos conectadas on line entre as diversas plantas da empresa (VEIGA, 2003).

No design dos carros, no nível operacional, observa-se a preocupação com a modularização no desmembramento do produto em módulos. No desenvolvimento do produto 
e, conseqüentemente, dos módulos são consideradas as seguintes etapas (VOLKSWAGEN, 2003b):

- análise de mercado/benchmarking;

- design preliminar (a mão livre);

- design no Photoshop;

- modelagem em clay;

- aplicação do software Icem Surf para a criação das referências digitais;

- interface e funções entre componentes;

- análise de composição de custos;

- sugestões de consumidores;

- execução do QFD (Desdobramento da Função Qualidade);

- sugestões de fornecedores no co-design;

- geração de idéias próprias;

- execução do FMEA (Análise de Possibilidade e do Efeito das Falhas);

- aplicação do software Catia para dimensionamento;

- formação do módulo;

- fabricação do protótipo;

- teardowns (teste destrutivo e análise com ultrassom);

- análise de custo real do produto; famílias.

- estruturação do módulo (interfaces entre componentes) e configuração para

A modularização do carro na Volkswagen caracteriza-se na sua divisão em oito módulos: frontend, denominação usada para designar a parte dianteira do carro, power train (grupo de componentes que gera a força e permite que o veículo desloque-se na superfície; inclui a transmissão, os diferenciais, o motor etc), portas, tampas e teto, combustível, carroceria, bancos e cockpit (nomenclatura usada no setor automotivo para designar o conjunto de painel e assentos dianteiros), sendo este último um dos principais e que tem uma proximidade maior com o consumidor (VOLKSWAGEN, 2004).

A modularização, no caso do Fox, atende o cliente que, ao optar por um determinado modelo, está optando por um número básico de itens de série. A customização começa a se configurar a partir do momento que o cliente faz uma escolha de pacote de opcionais. Por exemplo, o modelo 1.0 Plus Total Flex oferece a opção de escolha de tacômetro (conta-giros), airbag (equipamento de segurança em forma de balão inflável, sem denominação em língua portuguesa), CD player ( tocador de disco compacto), ar condicionado e freios. Tal escolha do consumidor leva a uma nova configuração do cockpit nos aspectos funcionais, com a inclusão de componentes e detalhes de monitoramento. A aparência dos produtos permanece a mesma, com exceção do Cross Fox e dos modelos para o mercado europeu. O primeiro apresenta 
detalhes de acabamento na cor prata, e no segundo existem textura da capa de cobertura diferenciada e tampa de porta-objetos (VEIGA, 2003).

\section{CONCLUSÃO}

No momento, a questão da modularização na Volkswagen, seja do ponto de vista da produção, seja do ponto de vista do produto, é definida estrategicamente, como se observa no estudo realizado. As duas competências, a modularização e o design, foram integradas por meio do manual de desenvolvimento do produto e, portanto, estão alinhadas. Além disso, conforme declarações da empresa, a modularização é considerada como elemento estratégico.

No entanto, por não desenvolver a gestão do design no nível estratégico e no nível tático, a integração da modularização com a customização ainda se dá de forma tímida. Observa-se que, no setor, conforme a literatura e confirmado no estudo de caso realizado, o design é uma atividade realizada predominantemente sob o ponto de vista formal.

Do ponto de vista da customização, pode-se observar também que o carro possui apenas oito módulos, e só recentemente a incorporação de dados dos consumidores, com o uso de programas informatizados, passou a ser desenvolvida de modo sistematizado para a sua possível utilização na customização. Portanto, o trabalho dos designers, hoje concentrado apenas na forma, poderia incorporar mais elementos de customização se a estrutura organizacional não o considerasse apenas como uma atividade do processo, desassociada do aspecto estratégico.

Observa-se que a pressão da competição pela melhoria forçou a introdução de uma arquitetura de produto interdependente de outros processos e setores, adquirindo características modulares. No caso do modelo Fox, essa arquitetura apoiou-se no projeto de uma família pequena de produtos. Maior destaque foi dado às questões produtivas, com os sistemas modulares de produção ou processo. Para atender a esse padrão, a empresa apresenta uma estrutura integrada, na qual os clientes foram consultados, a montadora e os "sistemistas" (denominação utilizada internamente na Volkswagen para designar cada participante do consórcio modular) tornaram-se partes correlacionadas e interdependentes, levando a uma administração geral do processo voltada para um mesmo horizonte de atuação.

No entanto, a modularização no processo, no caso do modelo Fox produzido na BUC, operado a partir de um sistema originado no Just in Time, o Sistema de Fabricação Integrada 
(FIS), adéqua-se também ao sistema modular de uso e de projeto. No caso da modularização no processo, o desempenho produtivo pode ser medido e corrigido a qualquer momento. Os "sistemistas" localizam-se no próprio pátio da empresa, denominado de Parque Industrial. No entanto, com respeito ao projeto, observa-se que, ao buscar a sustentabilidade, a empresa não integra a racionalização da produção, na qual a modularização poderia ser enfocada. Além disso, com respeito ao uso, observando o consumidor, ela pretende oferecer produtos mais atrativos, sem especificar que isso se dá por meio de customização e, portanto, entre outros aspectos, por modularização.

Com base nos dados coletados, pode-se dizer que, no projeto do Fox, os produtos centrais, conceito de Hamel e Prahalad (1995). são a sua plataforma e seu cockpit, comuns aos novos modelos da família Fox. De modo geral, a estratégia de modularização praticada pela montadora está focada em diminuir o número de fornecedores diretos, consistindo-se em uma prática voltada para a produção. Já a modularização utilizada na fase de desenvolvimento do produto traz o ganho em redução de tempo de projeto, embora se observe que os modelos não foram pensados originalmente de modo integral, como no caso do porta-luvas.

Constatou-se que a empresa Volkswagen encontra-se em um estágio ainda não pleno da utilização da modularização na medida em que não utiliza elementos de comunicação externa que permitem a customização em massa. Seguindo o estudo, uma forma de oferecer a customização seria uma maior modularização do produto, com mais módulos, além dos oito existentes. A diferenciação já existe entre modelos; porém, o cliente não tem a opção de configurar o carro conforme a sua escolha.

O estudo demonstra também que a Volkswagen do Brasil, no caso do modelo Fox, produzido na BUC, tem focado seus negócios nas atividades que geram maior valor agregado e que lhe conferem maiores vantagens competitivas: design, engenharia e marketing. Nessa busca, alinha-se com os dados teóricos que apontam o fato das empresas bem sucedidas tomarem a cadeia de valores como ponto central da sua estratégia, reconhecerem e responderem de modo rentável às necessidades não atendidas, reconhecendo e respondendo às tendências do macro-ambiente. Falta ainda, seguindo as teorias da gestão do design, fazer dele o seu pilar. 


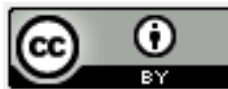

\section{REFERÊNCIAS}

ARBIX, G.; VEIGA, J. P. C. A distribuição de veículos sob fogo cruzado: em busca de um novo equilíbrio de poder no setor automotivo. Disponível em: <http://www.tela.com.br/html/montadoras.htm>. Acesso em: 16/10/2004.

ANDRADE, H. Reestruturação da manufatura e gestão operacional na Volkswagen. Monografia. Fundação Getúlio Vargas, São Paulo, 2003.

BLACKENFELT, M. Managing complexity by product modularization. Teases. $(\mathrm{PhD})$ Royal Institute of Technology, Stockholm, 2001.

CAMACHO, M. F. Diseño para el desarrollo: el potencial de la initeración estratégica del diseño en las empresas, el caso de Colombia. In: Congresso Brasileiro de Pesquisa e Desenvolvimento em Design, 6. Anais P\&D Design. São Paulo: FAAP, 2004. 1 CD.

FIXON, S. The multiple faces of modularity. Disponível em: <http://www.imvp.mit.edu/paper/02/fixson_multiplefaces.pdf>. Acesso em: 12/07/2005.

HAMEL, G.; PRAHALAD, C. K. Competindo pelo futuro. São Paulo: Campus, 1995.

HEIKKKILÄ, J. et all. Products and modularity. Centre of Helsinki University of Technology. $\quad 2002 . \quad$ Dspanha, em: <http://www2.uiah.fi/ tokarjal/productsandmodularity.pdf>. Acesso em: 10/03/2004.

HUANG, C. C. Overview of modular product development. ROC, v. 24, n. 3, 2000. Disponível em: <http://www2.nr.stic.gov.tw/ejournal/proceeding/v24n3/149-165.pdf.>. Acesso em: 30/07/2005.

ICSID. International Council of Societies of Industrial Design. Definition of design. Disponível em: <http://www.icsid.org/about/about/articles31.htm?query_page=1>. Acesso em: 20/05/2008.

KRUEGER, B. O Fox brilha nas ruas. Jornal da Volkswagen, São Paulo, p. 3, nov. 2003.

LARICA, N. J. Design de transportes: arte em função da mobilidade. Rio de Janeiro: 2AB, 2003.

MAERGNER, H. Devemos ter uma cultura de vitória. Jornal da Volkswagen, São Paulo, n. 118, p. 3, 2004.

MAGALHÃES, C. Design estratégico: integração e ação do design industrial dentro das empresas. Brasília: CNI, 1997.

MOZOTA, B. B. de. Design management: using design to build a brand value and corporate innovation. Nova York: Allworth Communications Inc., 2003.

PELEGRINI, A. V. O processo de modularização em embalagens orientado para a customização em massa: uma contribuição para a gestão do design. Dissertação (Mestrado). Programa de Pós-graduação em Engenharia Mecânica, Universidade Federal do Paraná, 2004. 
PINE, B. J. Personalizando produtos e serviços: customização maciça - a nova fronteira da competição dos negócios. São Paulo: Makron Books, 1994.

PORTER, M. E. Vantagem competitiva: Criando e sustentando um desempenho superior. Rio de Janeiro: Campus, 1989.

SAKO, M.; MURRAY, F. Modules in design, production and use: implications for the global automotive industry. Presented to International Motor Vehicle Program (IMVP) Annual Sponsors Meeting, Cambridge Massachusetts, USA, 5-7 Oct. 2000.

SALERNO, M. S. The characteristics and the role of modularity in the automotive business. International Journal of Automotive Technology and Management, Genebra, v. 1, n. 1, p. 92-107, 2002.

SALERNO, M. S. et al. Changes and persistence on the relationship between assemblers and suppliers in Brazil. Actes du Gerpisa, Paris, n. 24, p. 51-66, déc. 1998.

SANCHEZ, R. Using modularity to manage the interactions of technical and industrial design. Design Management Journal, Boston, v. 2, p. 9-19, 2002.

SANCHEZ, R.; COLLINS, R. P. Competing and learning in modular markets. Elsevier Science, Long Range Planning, London, p. 01-22, 2001. Disponível em: $<$ http://www.irpjournal.com>. Acesso em: 16/08/2003.

SANTOS, F. A. dos. O design como diferencial competitivo. Camboriú: Editora Univali, 2000.

SCHILLING, M. A. Toward a general modular systems theory and its application to interim product modularity. Academy of Management Review, New York, v. 25, n. 2, p. 312-334, 2000 .

SPARKE, P. A century of car design. London: Octopus, 2002.

TEIXEIRA, J. O design estratégico na melhoria da competitividade das empresas. Tese (Doutorado). Programa de Pós-graduação em Engenharia de Produção, Universidade Federal de Santa Catarina, Florianópolis, 2005.

TOVEY, M.; PORTER, S.; NEWTON, R. Sketching, concept development and automotive design. Design Issues, Massachusetts, v. 24, n. 2, p. 135-153, 2003.

TRUEMAN, M. Managing innovation by design: how a new design typology may facilitate the product development process in industrial companies and provide a competitive advantage. European Journal of Innovation Management, Bingley, v. 1, n. 1, p. 44-56, 1998.

VEIGA, L. A. Da prancheta para as ruas. Jornal da Volkswagen, São Paulo, n. 8, p. 6-7, ago. 2003.

VOLKSWAGEM do Brasil. Layout da planta de São José dos Pinhais. Disponível em: $<$ http://www.intranetbuc/nova_intranet>. Acesso em: 25/3/2005.

VOLKSWAGEN do Brasil. Jornal da Volkswagen, São Paulo, n. 4, 2003 a. 


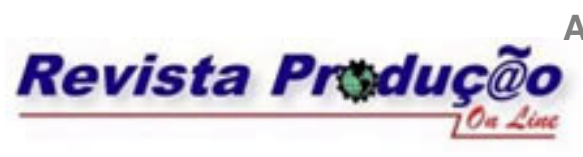

VOLKSWAGEN do Brasil. Manual k to k. São Paulo: Volkswagen do Brasil, 2003b.

VOLKSWAGEN do Brasil. Manual PEP. São Paulo: Volkswagen do Brasil, 2004.

WOMACK, J. P. A máquina que mudou o mundo. Rio de Janeiro: Campus, 1992.

WOLF, B. (Ed). Design management in der Industrie. Giessen: Anabas, 1994.

WOLF, B. Wilkhahn: a tradition of the cutting edge. Design Management Journal, Boston, p. 30, Spr., 2002.

WOLF, B. Estratégias para o sucesso no design de móveis. Curso de Extensão em Gestão do Design, Departamento de Design da Universidade Federal do Paraná, Curitiba, 18-29, ago. 2003. 